\title{
BLOQUEIO NO DESENVOLVIMENTO EMOCIONAL: DIÁLOGO ENTRE AS CONCEPÇÕES DE COURAÇA E FALSO SELF
}

\author{
Henrique Uva do Amaral \\ Universidade Estadual Paulista "Júlio de Mesquita Filho" (UNESP) - Campus de Assis \\ Diana Pancini de Sá Antunes Ribeiro \\ Universidade Estadual Paulista "Júlio de Mesquita Filho" (UNESP) - Campus de Assis \\ Jorge Luís Ferreira Abrão \\ Universidade Estadual Paulista "Júlio de Mesquita Filho" (UNESP) - Campus de Assis
}

\begin{abstract}
Resumo
Ao longo da literatura psicanalítica, observamos casos em que o analista encontra dificuldade ao lidar com certos tipos de pacientes, estes que apresentam pouca melhora sem um manejo especial. Baseando-se nisso, consideramos que Donald Winnicott e Wilhelm Reich trazem importantes contribuições para o tema, principalmente quando introduzem os conceitos de falso self e couraça. Nosso objetivo, portanto, delineia-se em estabelecer um breve diálogo entre estes conceitos, destacando algumas aproximações e distanciamentos. A metodologia de pesquisa se faz por meio do levantamento bibliográfico, sendo de natureza qualitativa e histórica. Ao final do trabalho, concluímos que os conceitos de couraça e falso self mais se aproximam do que se distanciam, na medida em que dizem respeito ao bloqueio emocional, da motilidade, da agressividade e da espontaneidade.
\end{abstract}

Palavras-chave: psicanálise; Donald Winnicott; Wilhelm Reich; couraça; falso self.

\section{BLOCKAGE ON EMOTIONAL DEVELOPMENT: DIALOGUE BETWEEN THE CONCEPTS OF ARMOR AND FALSE SELF}

\begin{abstract}
Throughout the psychoanalytic literature, we observe cases where the analyst finds difficulty to deal with some kind of patients, those who do not present a significant improvement without a special handling. Based on this, we consider that Donald Winnicott and Wilhelm Reich bring important contributions to the theme, especially when they introduce the concepts of false self and armor. Our objective, therefore, is to establish a short dialogue between these concepts, emphasizing some approximations and distinctions. The research methodology is done through a bibliographic survey, being of qualitative and historical nature. At the end of the work, we concluded that the concepts of armor and false self are more similar than they are different in relation to emotional, motility, aggressiveness and spontaneity blockage.

Keywords: psychoanalysis; Donald Winnicott; Wilhelm Reich; armor; false self.
\end{abstract}




\title{
BLOQUEO EN EL DESARROLLO EMOCIONAL: EL DIÁLOGO ENTRE LAS CONCEPCIONES DEL CORAZA Y FALSO SELF
}

\begin{abstract}
Resumen
A lo largo de la literatura psicoanalítica, hemos observado casos en los que al analista le resulta difícil trabajar con ciertos tipos de pacientes, estos que tienen poca mejora sin tratamiento especial. En base a esto, creemos que Donald Winnicott y Wilhelm Reich traen importantes contribuciones al tema, principalmente cuando introducen los conceptos de falso self y coraza. Nuestro objetivo, por tanto, se delinea en establecer un breve diálogo entre estos conceptos, destacando algunas aproximaciones y distanciamientos. La metodología de investigación se produce por medio del levantamiento bibliográfico, siendo de naturaleza cualitativa e histórica. Al final del trabajo, nosotros concluimos que los conceptos de coraza y falso self están más cerca que distantes en lo que se refiere al bloqueo emocional, la motilidad, la agresividad y la espontaneidad.
\end{abstract}

Palabras clave: psicoanálisis; Donald Winnicott; Wilhelm Reich; coraza; falso self.

\section{INTRODUÇÃO}

Ao longo da literatura psicanalítica, observamos casos em que o analista encontra dificuldade ao lidar com certos tipos de pacientes, estes que apresentam pouca melhora sem um manejo especial. Neste sentido, no artigo Limites - a questão do manejo clínico hoje, Cruz e Viana (2012) assinalam, pelo menos, dois tipos de pacientes que eram considerados inacessíveis ao tratamento psicanalítico: os que possuíam patologias narcísicas; e os denominados limítrofes (borderlines), caracterizados por patologias de estadoslimite, isto é, que tendiam à psicose. Para o presente trabalho, acrescentaríamos, ainda, aqueles em que há um forte bloqueio afetivo - os quais não precisam estar, necessariamente, situados fora do campo da neurose.

De acordo com Cruz e Viana (2012), a retomada desse problema é essencial para a clínica psicanalítica, tendo em vista que as psicopatologias mencionadas acima são muito recorrentes na contemporaneidade. Para os autores, deparamo-nos com indivíduos que não conseguem estabelecer um forte vínculo afetivo com o analista, ou que possuem dificuldade em se adequar às exigências do processo analítico (tais como a regra da associação-livre) ou, ainda, que sabotam o tratamento terapêutico (não comparecem às sessões, atrasam, reagem negativamente às intervenções do analista etc.), o que exigiria uma maior flexibilidade da técnica e do manejo em psicanálise. Baseando-se nisso, consideramos que Donald Winnicott e Wilhelm Reich podem trazer importantes contribuições para o tema, principalmente quando introduzem os conceitos de falso self e couraça.

No livro Análise do Caráter, Reich (1933/2001) discorre sobre vários casos clínicos em que seus pacientes não obtiveram melhoras significativas, mesmo após muitos anos de análise e da rememoração de conteúdos inconscientes. Ele observa que havia muita rigidez com relação ao comportamento e ao corpo, como se isso bloqueasse qualquer intervenção do analista. Na concepção do autor, diante dessa situação, era frequente que analistas afirmassem que "o 
paciente simplesmente não queria melhorar ou era 'narcísico demais'" (Reich, 1933/2001, p. 83).

Por sua vez, Winnicott (1945/1988) também mostra situações em que seus pacientes se sentiam tanto em falta de contato com o mundo externo quanto consigo mesmos, os quais, muitas vezes, não eram considerados adequados para análise. $\mathrm{E}$, ainda, afirma que "nunca o serão realmente, se não conseguirmos lidar com as dificuldades de transferência provocadas por uma falta essencial de relação verdadeira com a realidade externa" (Winnicott, 1945/1988, p. 279).

Mas o que seria isso que os autores mencionam não só dificultar o processo terapêutico mas, também, impedir o indíviduo de se sentir em contato com o mundo e consigo mesmo? E como isso surgiria?

Para entender estas questões, Reich nos fornece o conceito de couraça, enquanto Winnicott se utiliza da noção de falso self, sendo ambos originados do trabalho clínico destes autores. Nosso objetivo, portanto, delineia-se em compreender o desenvolvimento das concepções de couraça e falso self, a fim de estabelecer um breve diálogo entre estes conceitos, destacando algumas aproximações e distanciamentos.

Nossa escolha por esse diálogo se justifica pelo fato de que ambos os autores discutem problemáticas clínicas semelhantes, ainda que estejam partindo de diferentes paradigmas dentro do campo psicanalítico (os quais mencionaremos posteriormente). Dessa forma, ao nos utilizarmos do termo "bloqueio no desenvolvimento emocional", compreendemos que os conceitos de couraça e falso self não dizem respeito apenas ao bloqueio afetivo, mas, também, a uma interrupção do desenvolvimento emocional - visto que o crescimento do sujeito ocorre de uma forma reativa e intelectualizada, sendo pouco sentido como experiência e impulso pessoais.

Existem, é claro, importantes questões epistemológicas a serem consideradas entre Reich e Winnicott, no entanto, optamos por omiti-las no presente trabalho - não por negligência, mas porque elas merecem um estudo próprio, e mais detalhado, em outro momento. Assim, estamos cientes do caráter introdutório de nossa proposta, tendo em vista que enfatizamos a relação entre conceitos específicos.

\section{MÉTODO}

O presente artigo decorre de uma pesquisa, na qual a metodologia se fez por meio do levantamento bibliográfico, sendo de natureza qualitativa, histórica e teórico-conceitual. Neste estudo, destacamos os conceitos de couraça e falso self em obras específicas de Reich e Winnicott, desde os primeiros escritos aos últimos trabalhos. Em Reich, analisamos principalmente os livros: A Função do Orgasmo - Problemas Econômico-Sexuais da Energia Biológica (1942/1975); 
Análise do Caráter (1933/2001); e A Biopatia do Câncer (1948/2009). Em Winnicott, exploramos, em especial: Textos Selecionados: Da Pediatria à Psicanálise (1988); O Ambiente e os Processos de Maturação: Estudos sobre a Teoria do Desenvolvimento Emocional (1983); e A Natureza Humana (1988/1990). Ainda, levamos em consideração que ambos os autores se encontram em diferentes paradigmas, nos quais determinados conceitos freudianos podem ter sido aprofundados ou modificados (Abrão, 2007; Fulgencio, 2013).

Embora haja diferenças importantes entre Reich e Freud, Rego (2003) defende que o trabalho psicanalítico inicial reichiano se fundamenta, em grande parte, a partir da primeira teoria das pulsões de Freud. Neste sentido, Reich estaria relacionado ao paradigma pulsional, no qual se compreende que o funcionamento humano ocorre por meio de impulsos em direção à satisfação e à descarga - mesmo que por "um complexo sistema de investimentos e desvios" (Rego, 2005, p. 250) -, assim como de conflitos caracterizados pela oposição entre pulsão e defesa.

Por outro lado, Mezan (1996) situa Winnicott em outro paradigma, denominado paradigma objetal ou relacional. Este pressupõe que o indivíduo não busca puramente a satisfação, mas a relação com objetos. Em outras palavras, a experiência humana é analisada a partir do modo como se organizam as relações iniciais entre o bebê e outros seres humanos, além do papel do ambiente para a constituição do sujeito, o que significa dizer que as pulsões e a sexualidade deixam de ser centrais para a sua compreensão.

Dessa forma, tendo em vista que Reich e Winnicott se encontram em diferentes paradigmas, é importante que haja certo cuidado metodológico ao aproximar os conceitos de couraça e falso self. Sem a pretensão de entrar em detalhes sobre essas diferenças paradigmáticas, nosso método de análise segue, principalmente, as diretrizes propostas por Fulgencio (2013) no capítulo Metodologia de pesquisa em psicanálise na universidade.

De acordo com Fulgencio (2013), nosso trabalho poderia ser conceituado como uma pesquisa interparadigmática. Ao realizá-la, o autor afirma que podemos nos confrontar com dois problemas principais: "um problema semântico (a diferença de linguagem utilizada) e um problema de referência (a disparidade e correspondência entre os termos e seus objetos de referência)" (p. 60). Neste sentido, devemos estar sempre atentos aos referentes dos conceitos, dos problemas formulados pelos psicanalistas e das soluções encontradas em cada teoria. É importante, portanto, que explicitemos se a origem dos conceitos e o caminho percorrido por Reich e Winnicott são semelhantes. Nas palavras de Fulgencio (2013, p. 60): "Ao aproximar esses mundos, buscando referentes comuns, caberá sempre ao pesquisador explicar como faz estas passagens e quais critérios usa para conectar tais e tais referentes, mostrando que em um e em outro, ambos os paradigmas tratam do mesmo problema". 
A discussão e os resultados são organizados em três tópicos: no primeiro, denominado Ruptura no continuar a ser, descrevemos sobre as falhas no desenvolvimento emocional primitivo e a organização da defesa de falso self, segundo a teoria winnicottiana; no segundo, Do processo de encouraçamento à anorgonia, apresentamos os conceitos de couraça de caráter, couraça muscular e anorgonia, considerando também o contato de Reich com bebês e pacientes psicóticos; e, no último, intitulado como Bloqueio no desenvolvimento emocional: couraça e falso self, estabelecemos algumas aproximações e diferenciações entre estes conceitos, além de examinar seus aspectos saudáveis.

\title{
RUPTURA NO CONTINUAR A SER
}

Baseado em sua observação direta de bebês e do contato com pacientes psicóticos, Donald Winnicott (1945/1988) não só começa a diferenciar os pacientes neuróticos dos psicóticos, como, também, passa a mostrar a importância de se estudar um estádio anterior àquele em que o bebê se percebe como sujeito. Ele defende que os aspectos relacionados à identidade e continuidade de existência são processos que devem ser conquistados pelo bebê, mas que podem ser perdidos ou mesmo não ocorrerem.

\begin{abstract}
A localização do self no próprio corpo é frequentemente tida como certa; no entanto, uma paciente psicótica em análise veio a reconhecer que, quando era bebê, pensava que sua irmã gêmea do outro lado do carrinho era ela mesma. Sentia-se mesmo surpresa quando a irmã era pega no colo e ela permanecia onde estava. Seu sentido de self e de outro-que-não-o-self não se desenvolvera (Winnicott, 1945/1988, pp. 274-275).
\end{abstract}

Segundo Winnicott (1988/1990), para que o bebê possa se integrar em uma unidade (integração), além de sentir o self como localizado no próprio corpo (personalização) e diferenciar a realidade interna da realidade externa (realização), é necessário, primeiramente, que haja uma mãe suficientemente boa. Ou seja, é essencial que haja uma mãe (ou ambiente) que se adapte quase perfeitamente às necessidades do bebê, diminuindo essa adaptação sempre à medida que este possa suportar.

Essa adaptação diz respeito não apenas às necessidades fisiológicas, mas leva em consideração todos os detalhes de cuidado que possam proporcionar confiabilidade e segurança ao bebê. Destacam-se aqui a forma como a mãe olha, toca e segura o bebê, denominado holding, e, também, como o manipula (handling), enquanto este é cuidado. Segundo Winnicott (1945/1988, p. 276):

A tendência a integrar é ajudada por dois conjuntos de experiência: a técnica de cuidado infantil através da qual a temperatura do bebê é mantida, ele é manipulado, banhado, embalado e nomeado e, também, as experiências instintivas agudas que tendem a tornar a personalidade una a partir do interior. 
Simultaneamente ao holding e handling, é necessário que a mãe apresente o seio e os objetos exatamente no momento em que o bebê precisa, propiciando-Ihe, repetidamente, a ilusão de onipotência. Desse modo, visto que ele ainda não tem a capacidade de diferenciar o eu do não-eu, "a mãe torna possível para o bebê ter a ilusão de que o seio, e aquilo que o seio significa, foram criados pelo impulso originado na necessidade" (Winnicott, 1988/1990, p. 121). De acordo com o autor, é necessário que o bebê tenha passado por diversas experiências de ilusão, para que apenas depois, gradativamente, ele possa aceitar a desilusão.

A esse movimento que o bebê tem de criar os objetos, Winnicott denomina gesto espontâneo. Para o autor, os gestos espontâneos se relacionam à agressividade, o que, inicialmente, nada tem a ver com o sentimento de ódio, pois, ainda que possa ter uma qualidade destrutiva, isso dependeria de um ego mais desenvolvido. Para ele, essa agressividade diz respeito à atividade motora, sendo que "o ambiente é constantemente descoberto e redescoberto por causa da motilidade" (Winnicott, 1950-55/1988, p. 365). Assim, embora haja um componente interno que impulsiona o bebê a se integrar e se relacionar com objetos, é imprescíndivel que a mãe esteja lá para receber seu gesto espontâneo, bem como sobreviver aos seus impulsos agressivos (hostis ou não), proporcionando um ambiente de confiança.

No entanto, o que aconteceria com o bebê caso ele não tivesse a oportunidade de ter uma mãe suficientemente boa, ou se tivesse sido diversas vezes invadido pelo ambiente e não conseguisse prosseguir integrado e personalizado? É a isto o que o termo falso self vai se remeter.

Quando o bebê é cuidado suficientemente bem, a atividade mental surge para compensar as deficiências e fracassos do meio ambiente, de uma forma que ele possa compreender essas falhas, sem precisar perder seu sentido de ser e de existência (e ainda permitindo ser cuidado pela mãe). O problema vem quando essas falhas estão acima do nível que ele possa suportar, o que ele tomará como uma invasão. Neste último caso, a mente adotará um rumo diferente:

Certos tipos de fracasso materno, especialmente um comportamento irregular, produzem uma hiperatividade mental. Aqui, no crescimento excessivo da função mental como reação à maternagem inconstante, vemos que é possível o desenvolvimento de uma oposição entre a mente e o psique-soma, pois em reação a este estado anormal do meio ambiente, o pensamento do indivíduo começa a controlar e organizar os cuidados a serem dispensados ao psique-soma, ao passo que na saúde esta é uma função do meio ambiente (Winnicott, 1949a/1988, p. 414).

Essa ruptura é provocada por um mecanismo de defesa que Winnicott (1952/1988) se refere como desintegração, que faz com que o bebê tenha uma espécie de psicose - visto que ele ainda não se encontra integrado, personalizado e nem mesmo com senso de realidade - dividindo (splitting) o self em verdadeiro e falso self. 
O falso self se desenvolve na base da submissão, se adaptando aos padrões ambientais, sendo que "a sensação de futilidade e de irrealidade faz parte do desenvolvimento de um falso self que se desenvolve como proteção para o self verdadeiro" (Winnicott, 1954-5/1988, p. 470). Como somente o verdadeiro self pode se sentir real, temos aí uma interrupção no desenvolvimento pessoal e emocional.

A organização de um falso self não implica apenas um bloqueio no desenvolvimento emocional, mas, também, um congelamento da situação de fracasso (Winnicott, 1954-5/1988). É como se houvesse a esperança no indíviduo de que um dia aquela situação de fracasso pudesse ser reparada no presente real. Essa afirmação se justifica por meio dos relatos clínicos de Winnicott, em que ele presencia, por meio de um cuidado suficientemente bom, a regressão de seus pacientes à dependência e a situações desfavoráveis do desenvolvimento. Após sucessivas regressões, ele observa uma gradativa progressão no desenvolvimento e um abandono do falso self patológico.

Essa cisão pode aparecer muito cedo, até mesmo na vida intrauterina. Segundo Winnicott (1988/1990, p. 149), "a rigidez ou inadaptabilidade da mãe (devidas à ansiedade ou a um estado depressivo) podem, portanto, tornar-se evidentes para o bebê antes mesmo que este tenha nascido". Nesse sentido, dependendo da experiência do bebê no útero, ele poderia ter mais disposição a procurar o contato com o ambiente ou a se retrair.

Quando a desintegração ocorre na fase do nascimento, de acordo com o autor, poderia ocasionar em "perda temporária da identidade, [...] perda da continuidade do self e mesmo uma desesperança congênita (mas não herdada) com relação à conquista de uma vida pessoal" (Winnicott, 1949b/1988, p. 326). Como uma das formas de intrusão, ele destaca principalmente o fator tempo no parto - especialmente quando há muita demora, o que é sentido pelo bebê como um adiamento infinito ou de cair para sempre.

Se por um lado, na saúde, o bebê usa de sua agressividade e motilidade para criar e descobrir o mundo, por outro, a "motilidade, neste caso, é apenas experimentada como uma reação à invasão" (Winnicott, 1950-5, p. 365) e não como um impulso pessoal. Na verdade, na doença, "o potencial de motilidade só se torna uma experiência através da invasão do meio ambiente" (p. 366), por isso, também existe a submissão por parte do falso self. Portanto, podemos afirmar que há um certo bloqueio na motilidade espontânea do indivíduo com falso self. Tentemos agora compreender um pouco mais sobre qual é a relação entre verdadeiro e falso self e como eles se diferenciam.

O verdadeiro self, ou o núcleo do self, é considerado para Aiello-Vaisberg (2004, p. 49) como "um potencial criativo e uma organização dinâmica presente em todo ser humano, que se expressa basicamente por meio do gesto espontâneo e que possibilita que cada indivíduo seja a pessoa singular que é". Assim, apenas o verdadeiro self poderia ser criativo e se sentir real. 
Já o falso self, como nos indica Naffah Neto (2007), impede que o sujeito tenha qualquer experiência verdadeira com o ambiente. Muitas vezes, ocorre de ter uma função intelectual elevada, mas que é defensiva e dissociada do todo, além do que a experiência e funcionamento emocional se tornam empobrecidos, já que se encontram intocados. $\mathrm{E}$, embora ele se adapte muito bem ao ambiente, "pode-se dizer que se trata de uma personalidade sem alma, cuja característica maior é a aparência pura, destituída de sentido existencial: tudo parece ser, sem sê-lo verdadeiramente" (Naffah Neto, 2007, p. 83).

Assim, o falso self, a parte superficial e aparente do indivíduo, protegeria a existência do verdadeiro self, a parte espontânea e oculta, se adaptando aos padrões ambientais. "Deste modo é possível traçar o ponto de origem do falso self, que pode então ser visto como uma defesa, a defesa contra o que seria inimaginável, a exploração do self verdadeiro, que resultaria em seu aniquilamento" (Winnicott, 1960/1983, p. 134).

Tendo em vista essas considerações, poderíamos nos perguntar: para Winnicott, o falso self aparece apenas num estágio primitivo da vida - como no psicótico - ou ele pode aparecer em estágios posteriores? Essa organização defensiva diz respeito somente à patologia? Em outros trabalhos, observamos que Winnicott amplia o conceito de falso self. No entanto, antes de nos aprofundarmos nestas questões, consideramos importante apresentar o posicionamento de Reich sobre o tema.

\section{DO PROCESSO DE ENCOURAÇAMENTO À ANORGONIA}

Ao entrar em contato com pacientes bloqueados afetivamente, Wilhelm Reich percebe que, em muitos casos, a simples conscientização dos conteúdos inconscientes não era o bastante nem para a cura dos sintomas, nem para a irrupção dos afetos, ou mesmo para a condição geral do sujeito. De acordo com o autor, esses pacientes "podiam fazer associações, mas nenhum traço de emoção se revelava jamais. Todos os esforços ricocheteavam como se houvesse batido em 'uma parede grossa e dura'. Eles estavam 'encouraçados' contra qualquer ataque" (Reich, 1942/1975, p. 122). A partir de suas observações clínicas, ele conclui que é o caráter do paciente que traz dificuldade para o tratamento.

A noção de caráter nada tem a ver com aspectos morais ou éticos. Segundo Wagner (1996, p. 92), "o caráter é a forma típica (inconsciente) de o ego reagir para se defender", manifestando-se no comportamento característico de determinada pessoa, como a maneira de falar, a expressão facial, a postura corporal etc. Ele surge no sujeito como um mecanismo de defesa narcísico, que tem por finalidade a proteção do ego, seja contra os perigos do mundo externo ou contra os perigos implicados na satisfação das pulsões. 
Nesse caso, quando Reich menciona que é o caráter que traz dificuldade para a cura, ele está se referindo especificamente ao caráter neurótico. De acordo com o autor, o caráter neurótico se forma a partir da necessidade de recalcar as pulsões (resultado de um ambiente repressor), sendo que, ao manter uma defesa automática e operante, este passa a se enrijecer. Reich (1933/2001) descreve esse enrijecimento como uma espécie de couraça, "pois constitui claramente uma restrição à mobilidade psíquica da personalidade como um todo" (p. 151). O encouraçamento do sujeito neurótico se dá basicamente por meio de três processos:

1) Identifica-se com a realidade frustrante, personificada pela imagem da principal pessoa repressiva;

2) Volta contra si mesmo a agressão que mobilizou contra a pessoa repressiva e que também produziu angústia;

3) Desenvolve atitudes reativas contra os empenhos sexuais, isto é, utiliza de energia desses empenhos para servir a seus próprios objetivos, que é o de evitá-los (Reich, 1933/2001, p. 153).

Essa couraça possui uma estratificação, ou seja, se organiza de uma forma sistemática, histórica e estrutural, sendo que toda a história do paciente estaria "solidificada" sob a forma de atitudes de caráter, como em camadas geológicas. Nesse sentido, uma experiência ou uma situação traumática também poderia estar "congelada" na couraça. Isso se justifica pelo fato de que um conteúdo recalcado pode ser revivido na situação analítica logo que uma resistência de caráter tenha sido dissolvida (Dadoun, 1975/1991).

Para Reich (1942/1975, p. 130), "a energia que conservava a couraça unida era, habitualmente, uma tendência destrutiva inibida. Isso se comprovava pelo fato de que a agressão começava a soltar-se imediatamente, quando a couraça era penetrada". No entanto, é preciso compreender que, em sua concepção, agressão não significa o mesmo que sadismo ou destrutividade em seu sentido estrito. Ela se relaciona à ideia de atividade. Segundo o autor, "toda manifestação positiva de vida é agressiva" (Reich, 1942/1975, p. 137), afirmando que a "agressão é a expressão de vida da musculatura e do sistema de movimento" (p. 137). Assim, a destrutividade e hostilidade são movimentos agressivos, mas nem toda a agressividade é hostil ou destrutiva.

Logo, podemos admitir que, se por um lado, a couraça tem a função de proteção, por outro, ela é percebida pelo indivíduo como uma perda da espontaneidade e da capacidade para o prazer; como um sentimento de vazio e superficialidade; e pela falta de contato com o mundo e com as próprias sensações vegetativas. Isso não só contribui para o bloqueio emocional, mas, também, contra influências educacionais posteriores (Albertini, 1993). Acrescentando-se a isso, como sua motilidade se encontra bloqueada, o sujeito tem dificuldade de agir por conta própria, sendo dependente e passivo, principalmente com relação às figuras de autoridade. 
A partir desse processo, podemos considerar alguns conceitos importantes: um deles é o da falta de contato; e o outro é o de contato substituto. A falta de contato diz respeito à sensação de isolamento ou de insensibilidade interna, que, muitas vezes, é expressa como apatia e inflexibilidade. Ela surge a partir do conflito de forças opostas, entre o impulso em direção ao mundo externo e o impulso recalcado, "um fenômeno que corresponde à ocorrência de uma concentração ou densidade especial de antíteses e dissociações" (Reich, 1933/2001, p. 296, grifo do autor). Com o objetivo de evitar a angústia decorrente desse conflito de forças, o sujeito acaba perdendo muito da sensibilidade e motilidade.

Junto com a noção de falta de contato, é necessário que haja um contato substituto que fique no lugar de um impulso espontâneo. Tendo em vista que o "contato vegetativo imediato com o mundo foi mais ou menos destruído, quando seus vestígios restantes já não são mais suficientes para preservar a relação com o mundo externo, ou se desenvolvem funções substitutas ou há tentativas de estabelecer um contato substituto" (Reich, 1933/2001, p. 300, grifo do autor). Portanto, o contato substituto se mostra com uma parte falsa, artificial e superficial da personalidade que tenta se relacionar com o mundo externo.

Posteriormente, Reich (1933/2001) passa a observar que as defesas caracterológicas possuem um equivalente somático. Inicialmente, esse fato foi ilustrado por meio do contato com pacientes masoquistas, principalmente quando estes mostravam certo alívio da excitação e pressão interna no momento em que lhe batiam fisicamente. Mas, paralelamente a isso, ele constata que, à medida que a couraça de caráter vai sendo retirada, em todos os seus pacientes há uma mudança na expressão corporal e, também, uma relaxação das tensões musculares. Esses apontamentos o levam a concluir que "a energia da vida sexual pode ser contida por tensões musculares crônicas. A cólera e a angústia podem ser também bloqueadas por tensões musculares" (Reich, 1942/1975, p. 231, grifo do autor). Baseando-se nisso, ele cria o conceito de couraça muscular.

A couraça muscular surgiria da mesma forma e identicamente à couraça de cárater, como uma defesa contra a angústia, por meio de contrações musculares crônicas (Reich, 1948/2009). Estas contrações fariam com que o indíviduo, não apenas psicologicamente como, também, biologicamente, se sentisse amortecido e sem vida. Nas palavras do autor, a contração geral (simpaticotonia) "abrange todos os sistemas de órgãos, seus tecidos, o sistema sanguíneo, o endócrino, bem como a estrutura de caráter" (Reich, 1948/2009, p. 158).

Aqui, então, ele defende de uma forma mais concreta uma união funcional entre psique e o soma (embora, em alguns casos, o indivíduo não os perceba como uma unidade), sendo ambos governados pela energia biológica, denominando-a energia orgone (ver também A Biopatia do Câncer, de Reich, 1948/2009). Os movimentos mantidos por essa energia se relacionam aos 
sistemas nervosos simpático e parassimpático, de contração e expansão. 0 movimento de contração seria sentido pelo indivíduo como angústia, enquanto a expansão, como prazer (sexualidade). "Na excitação sexual, os vasos sanguíneos se dilatam. Na angústia, sente-se uma tensão interior centralizada como se fosse explodir, os vasos periféricos se contraem" (Reich, 1942/1975, p. 229). Assim, nessa perspectiva, os processos psíquicos teriam sempre uma equivalência funcional no campo somático, e o mesmo se valeria para o oposto.

Segundo Reich (1942/1975), a psicanálise se dedicou apenas "ao que a criança anula e aos motivos que a levam a aprender a controlar suas emoções. Não pesquisou o modo pelo qual as crianças habitualmente lutam contra os impulsos. É precisamente o processo fisiológico de repressão" (p. 256, grifo do autor) que as tensões musculares representam. Além disso, ele afirma que a outra forma de evitar as sensações corporais e a irrupção dos afetos é pelo controle da respiração. Em todo o sujeito de caráter neurótico haveria uma predominância do movimento inspiratório, em contraposição à superficialidade do movimento expiratório. "De fato, estava claro então que, como mecanismo fisiológico para a supressão e repressão dos afetos, a inibição respiratória era o mecanismo básico da neurose em geral" (Reich, 1942/1975, p. 263). Literalmente, a couraça muscular aprisiona, amortece e sufoca o sujeito.

No entanto, observamos que a questão do encouraçamento se torna mais complexa quando Reich (1948/2009) se depara com pacientes psicóticos e com câncer. Nestes últimos, ele observa que, mesmo quando se dissolvia a rigidez da couraça, apareciam fracas excitações e estes não melhoravam. "Uma observação cuidadosa do comportamento da paciente contradizia a suposição de que houvesse afetos reprimidos nas profundezas biológicas. Não havia afeto algum" (Reich, 1948/2009, p. 213). O autor conclui que, nesses casos, o bloqueio da energia não estaria tanto na periferia do organismo, mas, sim, em seu cerne, denominando-o anorgonia.

Segundo Reich (1948/2009, p. 353, grifo do autor), "o conceito de anorgonia abrange aquelas condições biopáticas que compartilham de uma fonte comum, qual seja, um bloqueio na mobilidade do plasma". De forma simples, se a noção de orgone diz respeito à energia, então, anorgonia pode ser entendida como "sem energia", morto, sem contato etc. Além disso, o termo se remete a um mecanismo de "contração rápida do aparelho vital" (Reich, 1948/2009, p. 409).

O autor descreve que todos os pacientes que sofriam ataques anorgonóticos já os haviam experimentado durante a primeira infância. Considerando que o bloqueio da energia estaria no cerne do organismo, o autor afirma que isso deve ter ocorrido quando as funções bioenergéticas ainda estavam se desenvolvendo, ou seja, no feto ou nos primeiros meses de vida (Reich, 1948/2009). 
Essa constatação é de suma importância para o pensamento do autor, pois ele esclarece que a angústia de cair nos pacientes psicóticos e com câncer é a mesma angústia de cair que ele observa em bebês. Nesse momento, ele conclui que a etiologia da psicose, na verdade, parte dos momentos mais iniciais da vida do bebê, que se distingue em vários fatores da etiologia da neurose. Segundo ele, "a orgonoterapia para esquizofrênicos, por exemplo, não deixa dúvidas de que os mecanismos centrais da doença se estabelecem durante as primeiras semanas de vida" (Reich, 1948/2009, p. 392, grifo do autor).

A anorgonia do bebê pode acontecer mesmo dentro do útero. Dependendo da rigidez caracterológica da mãe, partindo da mesma noção de tensões musculares, Reich (1948/2009) afirma que "é preciso supor que um útero livremente contrátil oferece um ambiente muito mais favorável para o embrião que um útero espástico e anorgonótico" (p. 406). Um útero contraído seria "sufocante" e "frio" para o feto, o que impediria um desenvolvimento orgonótico (energético) e, consequentemente, emocional, fazendo com que indivíduo se sentisse sem vida e sem esperança no futuro.

No tópico denominado "Angústia de cair em um bebê de três semanas", do livro A Biopatia do Câncer, Reich (1948/2009, p. 393) detalha o processo de anorgonia em um bebê recém-nascido, com um consequente encouraçamento, devido à falta de contato com a mãe e seu manejo inadequado. O autor descreve que "durante o ataque de angústia, a criança puxou os dois ombros para trás como que se protegendo da queda. Essa atitude se manteve; não conseguiu relaxar mesmo durantes os períodos livres de angústia" (Reich, 2009, p. 396).

Sem entrar em detalhes deste trabalho, apenas convém dizer que o processo de encouraçamento do bebê se dá de uma forma totalmente diferente daquela que ocorre em neuróticos, pois, segundo o próprio Reich (1948/2009, p. 397), "não há algo como um ego moral nessa idade e, de acordo com a teoria psicanalítica, quando não há defesa moral, também não pode haver angústia instintiva". Aqui, o encouraçamento ocorre por causa da angústia de cair, e não do choque entre impulso e defesa. Ainda, ele afirma que se houver um bloqueio energético por muito tempo nessa fase, o sujeito poderá desenvolver uma psicose ou, em casos extremos, esquizofrenia (quando a couraça é rompida).

Após essa breve explanação da teoria reichiana, surge-nos alguns questionamentos: haveria couraça também na saúde? No que o conceito de couraça se aproxima do de falso self? Como podemos discorrer sobre essas concepções? E no que ambos os autores podem contribuir um para o outro? Façamos agora um diálogo entre Reich e Winnicott.

\section{BLOQUEIO NO DESENVOLVIMENTO EMOCIONAL: COURAÇA E FALSO SELF}

Antes de mais nada, é importante destacar novamente alguns cuidados metodológicos, a fim de realizar esse diálogo. Em primeiro lugar, faz-se 
necessário não desconsiderar quaisquer contribuições feitas por ambos os autores, nem impor uma teoria sobre a outra e nem, tampouco, fazer com que entrem em perfeita harmonia. Em segundo lugar, é importante levar em consideração que Reich e Winnicott se localizam em diferentes paradigmas, dentro do campo psicanalítico: o primeiro se relaciona ao paradigma pulsional; e o último, ao paradigma objetal. Alguns aspectos dessa diferença paradigmática podem ser vistos em trabalhos como os de Loparic (2006, 2008), no entanto, tendo em vista que existem algumas diferenças entre Reich e Freud, esta discussão deverá ser postergada para outro momento. E, por último, conforme afirma Fulgencio (2013), devemos estar atentos "ao referente dos conceitos utilizados, dos problemas formulados e das soluções propostas e/ou encontradas em cada quadro de referência" (p. 61).

Em Reich e Winnicott, as perguntas poderiam ser formuladas dessa forma, por exemplo: o resultado terapêutico obtido por um paciente que não precisa mais de um falso self patológico, como é relatado por Winnicott, é o mesmo que o de um paciente em que a rigidez de sua couraça foi dissolvida, como descrito por Reich? Quando os autores apresentam os casos clínicos a partir desses conceitos, eles estão falando do mesmo tipo de psicopatologia, como psicose e neurose? A compreensão sobre a diferença entre psicose e neurose é semelhante? Agressividade tem o mesmo sentido para ambos?

$\mathrm{Na}$ verdade, é possível afirmar que, à medida que nos aprofundamos nesses conceitos ao longo de toda a obra desses autores, o diálogo entre eles se torna mais complexo, pois podemos ter um falso self que não tem origem necessariamente psicótica, e, ao mesmo tempo, um processo de encouraçamento que difere dos sujeitos neuróticos. Tendo posto isso, estabeleceremos, primeiramente, algumas aproximações.

\section{Sem contato, sem vida - Aproximações}

Quando estudamos o conceito de couraça e falso self, talvez o aspecto que tenha mais proximidade se apresente enquanto fenômeno clínico. Isso aparece claramente no livro Psicoterapia Dinâmica Intensiva Breve, em que, ao trazer o trabalho de Habib Davanloo, Malan e Selva (2008) descrevem esse fenômeno como "defesas contra proximidade emocional", afirmando que "Reich referiu-se a elas como 'couraça caracterológica', enquanto Winnicott usou o termo 'falso self'" (p. 20).

Em Reich, essa afirmação fica clara quando retomamos o conceito de falta de contato, que se caracteriza por um sentimento de isolamento interno, insensibilidade, apatia e por uma tendência a se refugiar dentro de si mesmo. Nas palavras do autor, "demonstrou-se que essas atitudes não só cumpriam a função de manter reprimidas as tendências agressivas recalcadas, mas, sobretudo, compensavam seu distanciamento interno em relação ao mundo" (Reich, 1933/2001, p. 290). Além disso, ele afirma que o intelecto pode ter uma 
função defensiva, ou seja, "pode ser estruturado e dirigido de maneira a parecer um hábil aparelho, cujo fim é precisamente evitar a cognição, isto é, assemelhase a uma atividade que nos afasta da realidade" (Reich, 1933/2001, p. 285, grifo do autor), sendo esta mais uma aproximação com a concepção de falso self.

Em Winnicott, embora o conceito de falso self seja bem mais complexo, entendê-lo como "defesa contra proximidade emocional" também parece ser válido. Aqui, apenas acrescentaríamos que o medo dessa proximidade emocional se refere, também, ao medo de aniquilação do verdadeiro self. Segundo o autor, é muito frequente que o sujeito com falso self tenha uma função intelectual elevada, no entanto, caso essa ruptura ocorra num estágio primitivo de desenvolvimento, ela "é patologicamente desligada do corpo com suas funções, e dos sentimentos, pulsões e sensações do ego total" (Winnicott, 1949b/1988, p. 328).

A ideia de falta de contato nos leva irremediavelmente para o conceito de "contato substituto" reichiano, sendo eles, é claro, inseparáveis. Em sua dissertação denominada O Afeto: uma unidade psicossomática: Freud, Reich e Winnicott, Castel (2008) procura mostrar que Reich e Winnicott defendem a existência de uma base fisiológica das emoções, além da indissociação e complementaridade entre psique e soma. Ainda, compara os conceitos de fluxo energético em Reich e vir a ser em Winnicott, já que apresentariam a "ideia de existir uma unidade psíquica/somática e que essa unidade se apresenta como um fluxo" (p. 129). Para o autor, quando esse fluxo é interrompido de alguma forma, como por uma intrusão, o sujeito criaria um contato substituto, a partir da couraça, para Reich, ou um falso self, para Winnicott, se adaptando passivamente aos padrões ambientais: "Esse conceito de contato substituto se aproxima muito do desenvolvido por Winnicott de falso self" (Castel, 2008, p. 119). Na verdade, estamos falando aqui de um aspecto falso, artificial e superficial da personalidade que tem de se relacionar com o mundo, seja para defender o verdadeiro self, seja porque o "contato vegetativo imediato com o mundo foi mais ou menos destruído" (Reich, 1933/2001, p. 300). Embora essa aproximação possua ressalvas, estas serão assinaladas mais à frente.

A partir disso, podemos identificar que, tanto no sujeito encouraçado quanto naquele com falso self, falta autonomia, espontaneidade e criatividade. Em outras palavras, o sujeito está sempre sendo passivo e se submetendo às exigências do mundo externo, ou, em termos winnicottianos, ele apenas pode experimentar o mundo reagindo às invasões, e não por meio de impulso pessoal. Ele não vive; sobrevive.

Aqui, nos parece pertinente a consideração de Cornell (1998) sobre o processo de encouraçamento, apresentado no artigo Se Reich Tivesse Encontrado Winnicott: o Gesto Interrompido. Segundo o autor, o encouraçamento pode ser compreendido "como sendo a interrupção dos 'gestos espontâneos', tanto das atividades somáticas quanto das atividades interpessoais 
da criança em desenvolvimento" (Cornell, 1998, p. 94). Essa interpretação parece ser verdadeira, se considerarmos que o gesto espontâneo tem a ver com a agressividade, em Winnicott. Tendo em vista que, em ambos os autores, a agressividade se relaciona à atividade motora, podemos observar que tanto na couraça quanto no falso self existe um bloqueio da motilidade $\mathrm{e}$, consequentemente, da agressividade e espontaneidade.

\section{Ser ou não-ser - Diferenciações}

Inicialmente, quando observamos os resultados terapêuticos descritos por Reich e Winnicott, assim que a rigidez da couraça é dissolvida ou quando o paciente não precisa mais se utilizar do falso self, notamos o aumento da espontaneidade e do sentimento de estar vivo. Todavia, por outro lado, vemos que a postura do sujeito diante do mundo se distingue nos dois casos. Para Winnicott (1954-55/1988), o sujeito nesse caso mostra certa ingenuidade, como se tivesse acabado de nascer. Aqui, a sensação de ser e de existir são sentidos como conquista, antes mesmo de qualquer reconhecimento da vida instintual.

[...] Pela primeira vez na vida do paciente, há agora a possibilidade do desenvolvimento de um ego, de sua integração a partir dos núcleos egóicos, da sua consolidação como um ego corporal, e também do repúdio ao ambiente externo, dando início a uma relacionabilidade com objetos. Pela primeira vez o ego pode viver impulsos do id e sentir-se real ao fazê-lo, e sentir-se real também ao descansar dessas experiências (Winnicott, 1955-56/1988, p. 488).

Para Reich (1942/1975), o paciente em que a rigidez da couraça foi dissolvida se mostra forte o bastante para perseguir seus objetivos, além de defender suas exigências pulsionais, mesmo que, muitas vezes, elas se contradigam com a moral vigente. A sensação de existir e a integração aqui já são um fato.

[...] A pessoa com uma estrutura auto-regulada e sã não se adapta à parte irracional do mundo; insiste na satisfação de seus direitos naturais. Parece doente e anti-social aos moralistas neuróticos. $\mathrm{Na}$ realidade, é incapaz de praticar ações anti-sociais. Desenvolve uma confiança natural, baseada na sua potência sexual (Reich, 1942/1975, p. 159).

A partir disso, podemos enfatizar duas diferenças principais: a importância que Reich dá à questão da genitalidade, algo secundário e pouco comentado por Winnicott; e, especialmente, sobre a fragilidade do ego nos pacientes que Winnicott descreve, ao contrário dos que se estruturam pelo chamado caráter genital (modelo de saúde apresentado por Reich). Tendo em vista que a noção de genitalidade em Reich é complexa demais para ser abordada neste trabalho, destacaremos aqui apenas a questão da constituição do ego.

$\mathrm{Na}$ tese Memórias de um Desterro - Corporeidade na Clínica Contemporânea, Cotta (2010) traz uma crítica à clínica reichiana e "neoreichiana", afirmando que elas não contemplam "um adequado entendimento da 
compreensão dos distúrbios contemporâneos, os quais muito pouco têm a ver com a vida pulsional, mas, isto sim, dizem de sofrimentos relativos à existência humana" (p. 26). Para o autor, o paradigma pulsional concebe o ego como autoconstituído "e, consequentemente, não coloca em questão a necessidade de uma 'maternagem suficientemente boa' para o estabelecimento do ego" (Cotta, 2010, p. 70). Isso significaria dizer que, para estas teorias, a relação com o outro tem um papel muito pequeno na constituição do sujeito.

$\mathrm{Na}$ concepção desse mesmo autor, embora possa ser falado de um congelamento de uma situação traumática na couraça, e de um congelamento quando o falso self aparece, estes seriam essencialmente diferentes, pois se tratam de fenômenos distintos. O primeiro diz respeito à vida pulsional e o outro à questão da existência. Ainda, ele afirma que, nas teorias reichianas, o sujeito se defenderia contra ansiedade de castração, típica de uma psicopatologia neurótica; enquanto, em Winnicott, o sujeito se defenderia contra ansiedade de aniquilação ou de agonias impensáveis, típica da psicose. Nas palavras de Cotta (2010, p. 67, grifo do autor):

[...] É aqui que é importante introduzir uma problematização: observa-se que na clínica a teoria reichiana e neo-reichiana não dão conta de muitos quadros clínicos contemporâneos, principalmente, os chamados distúrbios limítrofes.

O que a imensa maioria de pacientes se queixa não é de problemas tipicamente neuróticos, relativos à inveja, competição e rivalidade. Suas queixas dizem respeito a vivências de não terem identidade própria, a sensações de viverem fora do corpo, de não terem um corpo.

Assim, a diferença essencial entre esses conceitos é também paradigmática, isto é, se distinguem mais no que diz respeito à psicopatologia e à constituição do ego. No entanto, é preciso fazer ressalvas. Em primeiro lugar, embora seja clinicamente relevante, compreendemos que a crítica de Cotta (2010) é teoricamente incompleta, pois não aborda o livro A Biopatia do Câncer, no qual Reich (1948/2009) traz considerações importantes sobre a psicose.

Desse modo, não concordamos totalmente com Cotta (2010) quando ele critica a relação entre o congelamento presente na couraça e o congelamento que ocorre na organização de falso self. É verdade que o conceito de couraça individualmente não dá conta dessa relação, no entanto, percebemos que é possível uma aproximação entre o congelamento da situação de fracasso do ambiente, quando há falso self, e a concepção de anorgonia, em que a couraça se formaria secundariamente. Isso é reforçado por Reich (1948/2009) quando afirma que "a futilidade caracterológica e o embotamento afetivo eram couraças superficiais. A anorgonia foi e permaneceu sendo o mecanismo profundo" ( $p$. 389). Neste caso, o bloqueio da energia ocorreria mais no cerne do organismo do que em sua periferia (couraça), indicando um "congelamento" diferente do que ocorre em neuróticos. 
Também discordamos de Cotta (2010) quando este afirma que Reich apenas descreve sujeitos que se defendem contra ansiedade de castração. Como mencionado anteriormente, ao entrar em contato com pacientes com anorgonia, Reich observa uma angústia de cair que é sentida como um processo mortífero, um colapso total do organismo, sendo totalmente diferente da angústia de cair que ocorre em sujeitos neuróticos. Assim como Winnicott (1963/1994) relata sobre as agonias primitivas, Reich (1948/2009) fala sobre o medo de despedaçamento de uma paciente: "Confinar-se ao leito era um tremendo mecanismo de defesa projetado para protegê-la contra esse medo de 'despedaçar-se'. O perigo de 'se despedaçar' ficou presente quando o espasmo diafragmático estava a ponto de se dissolver em contrações clônicas" (p. 182).

Além disso, ao nos aprofundar na obra de Donald Winnicott (1960/1983), percebemos que a organização de falso self pode se dar em estágios posteriores do desenvolvimento, e não apenas em psicóticos. Dessa forma, mesmo que existam diferenças iniciais entre os conceitos de couraça e de falso self, em termos de psicopatologia e constituição do ego, compreendemos que essas diferenças não representam o todo.

\section{Couraça e falso self na saúde}

Até o presente momento, falamos a maior parte do tempo sobre o conceito de falso self e couraça como sendo patológicos, mas pouco foi discutido sobre seu aspecto considerado saudável. No que diz respeito a esse tema, notamos que, em grande parte, Reich e Winnicott o entendem da mesma forma. Para eles, possuir um falso self ou couraça na saúde, é ter mais ou menos consciência de quando e porque isso ocorre, além de ter mais controle sobre esse mecanismo de defesa.

No artigo denominado Distorção do ego em termos de falso e verdadeiro "self", Winnicott (1960/1983, pp. 130-131) defende que existem vários "estágios" de organização do falso self, dentre os quais se encontraria também a normalidade. O autor afirma que, na normalidade, "o falso self é representado pela organização integral da atitude social polida e amável, um 'não usar o coração na manga', como se poderia dizer" (Winnicott, 1960/1983, p. 131). Segundo ele, a habilidade de conciliação do indíviduo de se submeter às "boas maneiras sociais" e, ao mesmo tempo, não se expor, também pode ser considerada uma conquista, o que garante um lugar na sociedade. No entanto, ele reconhece que "ao mesmo tempo, na normalidade, a conciliação deixa de ser aceitável quando as questões se tornam cruciais. Quando isso acontece o self verdadeiro é capaz de se sobrepor ao self conciliador" (p. 137).

Além da questão de ter mais controle do falso self, vemos que uma das diferenciações que ele faz entre o extremo da doença e o da saúde é sobre a capacidade que o sujeito tem de ser espontâneo e criativo e, mais do que isso, "de viver em uma área intermediária entre o sonho e a realidade, aquela que é 
chamada de vida cultural" (Winnicott, 1960/1983, p. 137), o que não é possível quando ocorre um alto grau de splitting.

Para Reich, se por um lado, a couraça na patologia é representada por sua rigidez, na saúde, ela é flexível. Nas palavras do autor, "o ego do caráter genital também apresenta uma couraça, mas ele a controla, não está à sua mercê. A couraça é flexível o bastante para se adaptar às mais diversas experiências" (Reich, 1933/2001, p. 175). Essa adaptação diz respeito à capacidade que o indivíduo tem de se abrir ao mundo de forma tão intensa quanto se fechar, se necessário, e, acima de tudo, de sua capacidade de entrega: seja em uma experiência sexual, ou no trabalho ou numa atividade cultural. Além disso, o caráter genital "é capaz de criticar e de modificar a situação social" (Reich, 1933/2001, p. 176), quando esta não condiz com suas exigências pulsionais.

Ainda que fosse importante analisar a diferença entre o caráter neurótico e o caráter genital, principalmente a teoria do orgasmo, consideramos que o assunto extrapolaria os limites deste artigo. Dessa forma, gostaríamos de apresentar agora algumas considerações finais, com o intuito de possibilitar futuras reflexões e desenvolvimentos concernentes ao diálogo entre Winnicott e Reich.

\section{CONSIDERAÇÕES FINAIS}

Ao longo deste trabalho, observamos que, apesar das diferenças teóricas e paradigmáticas entre os autores, estamos falando de um mesmo problema: o bloqueio no desenvolvimento emocional. Quando esse bloqueio ocorre, o indivíduo é impedido de prosseguir em seu desenvolvimento emocional, ou seja, em maior ou menor grau, ele deixa de ter um contato afetivo e verdadeiro com o mundo externo, com os próprios sentimentos e, também, na relação com o próprio corpo.

A partir disso, concluímos que os conceitos de couraça e falso self mais se aproximam do que se distanciam, na medida em que dizem respeito não apenas ao bloqueio emocional, mas, também, ao bloqueio da agressividade, da motilidade e da espontaneidade, além de ser a parte falsa e superficial da personalidade que se relaciona passivamente com o mundo. Também vemos aproximações em seus aspectos considerados saudáveis, como pela flexibilidade da defesa.

As maiores diferenças se dão quando comparamos com a concepção de falso self em sujeitos psicóticos, pois falam sobre a constituição do ego, algo que Reich não leva em consideração. Ainda que existam aproximações entre a desintegração no falso self e o conceito de anorgonia, consideramos que faltam muitas questões relativas principalmente à integração, personalização e realização a serem abordadas pela teoria reichiana. No entanto, como existem 
graus de falso self, compreendemos que essas diferenças não representam o todo.

Outro ponto interessante a ser mencionado é que a formulação dos conceitos de couraça e falso self refletem, em grande parte, a postura dos analistas perante seus pacientes. Enquanto a couraça é uma "armadura" (do inglês armor), como uma parede grossa, dura e inflexível, exigindo uma postura mais confrontadora do analista, o falso self é um "cuidador" do verdadeiro self, necessitando de uma postura mais acolhedora do ambiente. Nesse sentido, compreendemos que um autor pode contribuir fortemente para acrescentar, complementar e auxiliar a repensar o outro, sem que seja necessária uma conversão ou harmonia de teorias.

Dentre as concepções a serem desenvolvidas e enriquecidas a partir do diálogo entre Reich e Winnicott, em pesquisas futuras, podemos destacar: corporeidade, sexualidade, relacionamento humano, desenvolvimento emocional, tratamento e prevenção de psicopatologias, técnicas terapêuticas, saúde psíquica, educação etc.

Tendo em vista que ainda há muitos conceitos a serem abordados, este artigo não pretende esgotar o assunto. Na verdade, notamos que ele introduz a uma série de novas questões: existiriam outros paralelos teóricos na teoria reichiana em que o conceito de falso self se mostra mais amplo que o de couraça, principalmente com relação à integração, personalização e realização? E o contrário? Se o conceito de couraça também aborda a questão psicossomática, como pelas tensões musculares, pela respiração e pela relação com o sistema cardiovascular, poderíamos afirmar que Winnicott traz essa problemática para a noção de falso self? O falso self também poderia aparecer em sujeitos neuróticos? Como essa discussão poderia contribuir para a prática clínica nas duas abordagens? E, além disso, no que ambos os autores poderiam contribuir para uma clínica na atualidade?

Certamente, existem muitas outras perguntas que podem surgir a partir desse diálogo, porém, a fim de encerrar nossa discussão, poderíamos fazer as últimas: o que é o verdadeiro self? E o que está além da couraça? Para os autores, isso seria o mesmo que descrever sobre o que é a vida. Segundo Winnicott (1960/1983, p. 136), "não há sentido na formulação da idéia do self verdadeiro, exceto com o propósito de tentar compreender o falso self, porque ele não faz mais do que reunir os pormenores da experiência de viver". Além do mais, de acordo com Reich (1933/2001, p. 333, grifo do autor):

Apesar da linguagem refletir o estado emocional plasmático de maneira imediata, ela não é capaz de alcançar esse estado em si. A razão disso é que o funcionamento da vida é muito mais profundo do que a linguagem e está além dela. 


\section{REFERÊNCIAS}

Abrão, J. L. F. (2007). Por um modelo metodológico de historiografia da psicanálise. Revista Pulsional, 20(189), 5-16.

Aiello-Vaisberg, T. M. J. (2004). Ser e fazer: Enquadres diferenciados na clínica winnicottiana. Aparecida: Idéias e Letras.

Albertini, P. (1993). Reich: História das Idéias e Formulações para a Educação. São Paulo: Ágora.

Castel, P. V. (2008). O afeto: uma unidade psicossomática: Freud, Reich e Winnicott (Dissertação de Mestrado). Universidade do Estado do Rio de Janeiro, Rio de Janeiro.

Cornell, W. F. (1998). Se Reich tivesse encontrado Winnicott: O gesto interrompido. Revista Reichiana, 7, 80-97.

Cotta, J. A. M. (2010). Memórias de um desterro: corporeidade na clínica contemporânea (Tese de Doutorado). Pontifícia Universidade Católica de São Paulo, São Paulo.

Cruz, W. F. O.; Viana, T. C. (2012). Limites - A Questão do Manejo Clínico Hoje. Psicologia Clínica, 24(11), 27-41. doi:10.1590/S0103-56652012000200003.

Dadoun, R. (1991). Cem Flores para Wilhelm Reich. São Paulo: Moraes (trabalho original publicado em 1975).

Fulgencio, L. (2013). Metodologia de pesquisa em psicanálise na universidade. In C. A. Serralha, \& F. Scorsolini-Comin (Eds.), Psicanálise e universidade: Um encontro na pesquisa (pp. 25-66). Curitiba: CRV.

Loparic, Z. (2006). De Freud a Winnicott: aspectos de uma mudança paradigmática. Winnicott E-Prints, 1(1), 1-29. Recuperado em 01 de abril de 2018, de

http://pepsic.bvsalud.org/scielo.php?script=sci arttext\&pid=S1679-

$432 \times 2006000100004 \&$ lng $=p t \& t$ lng $=p t$.

Loparic, Z. (2008). O Paradigma Winnicottiano e o Futuro da Psicanálise. Revista Brasileira de Psicanálise, 42(1), 137-150. Recuperado em 01 de abril de 2018, de

http://pepsic.bvsalud.org/scielo.php?script=sci arttext\&pid=S0486641X2008000100014\&lng=pt\&tlng=pt.

Malan, D.; Selva, P. C. D. (2008). Psicoterapia dinâmica intensiva breve: um método inovador. Porto Alegre: Artmed.

Mezan, R. (1996). Paradigmas e modelos na Psicanálise atual. In Pellanda, N. M. C. ; Pellanda, L. E. C. (Org.), Psicanálise Hoje: Uma Revolução do Olhar (pp. 347-355). Petrópolis: Vozes. 
Naffah Neto, A. N. (2007). A problemática do falso self em pacientes de tipo borderline: revisitando Winnicott. Revista Brasileira de Psicanálise, 41(4), 77-88. Recuperado em 01 de abril de 2018, de http://pepsic.bvsalud.org/scielo.php?script=sci arttext\&pid=S0486$641 \times 2007000400008 \& \operatorname{lng}=p t \& t \operatorname{lng}=p t$.

Rego, R. A. (2003). A clínica pulsional de Wilhelm Reich: uma tentativa de atualização. Psicologia USP, 14(2), 35-59.

Rego, R. A. (2005). Psicanálise e Biologia: uma discussão da pulsão de norte em Freud e Reich (Tese de Doutorado). Instituto de Psicologia da Universidade de São Paulo, São Paulo.

Reich, W. (1975). A Função do Orgasmo: Problemas Econômico-Sexuais da Energia Biológica. São Paulo: Círculo do Livro. (Trabalho original publicado em 1942).

Reich, W. (2001). Análise do Caráter. São Paulo: Martins Fontes. (Trabalho original publicado em 1933).

Reich, W. (2009). A Biopatia do Câncer. São Paulo: Martins Fontes. (Trabalho original publicado em 1948).

Wagner, C. M. (1996). Freud e Reich: Continuidade ou Ruptura?. São Paulo: Summus.

Winnicott, D. W. (1983). Distorção do ego em termos de falso e verdadeiro self. In D. W. Winnicott (Org.), O ambiente e os processos de maturação: Estudos sobre a teoria do desenvolvimento emocional (pp. 128-139). Porto Alegre: Artes Médicas. (Trabalho original publicado em 1960).

Winnicott, D. W. (1988). Desenvolvimento emocional primitivo. In D. W. Winnicott (Org.), Textos Selecionados: da Pediatria à Psicanálise (pp. 269285). Rio de Janeiro: Francisco Alves. (Trabalho original publicado em 1945).

Winnicott, D. W. (1988). A mente e sua relação com o psique-soma. In D. W. Winnicott (Org.), Textos Selecionados: da Pediatria à Psicanálise (pp. 409425). Rio de Janeiro: Francisco Alves. (Trabalho original publicado em 1949a).

Winnicott, D. W. (1988). Recordações do nascimento, trauma do nascimento e ansiedade. In D. W. Winnicott (Org.), Textos Selecionados: da Pediatria à Psicanálise (pp. 313-340). Rio de Janeiro: Francisco Alves. (Trabalho original publicado em 1949b).

Winnicott, D. W. (1988). Agressão e sua relação com o desenvolvimento emocional. In D. W. Winnicott (Org.), Textos Selecionados: da Pediatria à Psicanálise (pp. 355-374). Rio de Janeiro: Francisco Alves. (Trabalho original publicado em 1950-1955).

Winnicott, D. W. (1988). Psicose e cuidados maternos. In D. W. Winnicott (Org.), Textos Selecionados: da Pediatria à Psicanálise (pp. 375-388). Rio de Janeiro: Francisco Alves. (Trabalho original publicado em 1952). 
Winnicott, D. W. (1988). Aspectos clínicos e metapsicológicos da regressão dentro do setting psicanalítico. In D. W. Winnicott (Org.), Textos Selecionados: da Pediatria à Psicanálise (pp. 459-482). Rio de Janeiro: Francisco Alves. (Trabalho original publicado em 1954-1955).

Winnicott, D. W. (1988). Variedades clínicas da transferência. In D. W. Winnicott (Org.), Textos Selecionados: da Pediatria à Psicanálise (pp. 483-490). Rio de Janeiro: Francisco Alves. (Trabalho original publicado em 1955-1956).

Winnicott, D. W. (1990). Natureza Humana. Rio de Janeiro: Imago. (Trabalho original publicado em 1988).

Winnicott, D. W. (1994). O Medo do Colapso. In C. Winnicott, R. Shepherd \& M. Davis (Orgs.), Explorações psicanalíticas (pp. 70-76). Porto Alegre: Artes Médicas. (Trabalho original publicado em 1963).

Sobre os autores

Henrique Uva do Amaral é Psicólogo e mestre em psicologia pela Universidade Estadual Paulista de Assis. henrique.uvaa@gmail.com

Diana Pancini de Sá Antunes Ribeiro é Psicóloga pela Universidade Estadual Paulista de Assis, mestre em psicologia pela Universidade de São Paulo e doutora em psicologia pela Pontifícia Universidade Católica de Campinas. Professora Assistente Doutora do Departamento de Psicologia Clínica e Coordenadora do curso de Psicologia da Universidade Estadual Paulista de Assis, gestão 20152018. diana@assis.unesp.br

Jorge Luís Ferreira Abrão é Psicólogo pela Universidade Estadual Paulista de Assis, mestre em psicologia pela Universidade Estadual Paulista de Assis, doutor em psicologia pela Universidade de São Paulo e livre-docente em psicologia pela Universidade Estadual Paulista de Assis. Professor Adjunto Doutor do Departamento de Psicologia Clínica e do Programa de Pós-Graduação em Psicologia da Universidade Estadual Paulista de Assis. abrao@assis.unesp.br

A contribuição de cada autor pode ser atribuída como se segue: Amaral, Ribeiro e Abrão contribuíram para a conceitualização, investigação e visualização do artigo; Amaral foi responsável pela obtenção de financiamento; Amaral, Ribeiro e Abrão fizeram a redação inicial do artigo (rascunho) e Amaral, Ribeiro e Abrão são os responsáveis pela redação final (revisão e edição).

Os autores agradecem a FAPESP pelo financiamento da pesquisa ( $\mathrm{n}^{\circ}$ do processo: 2014/14769-7).

Recebido em: 28/04/2017

$1^{\text {a }}$ revisão em: $30 / 03 / 2018$

Aceito em: 01/05/2018 